\title{
INVESTIGATING THE MECHANISM OF CONFRONTING EARTHQUAKE CRISIS, WITH THE APPROACH OF REHABILITATION OF URBAN WORN TEXTURES
}

\author{
Asma Shivaei \\ Urban planning, Art and Architecture, Kerman Azad University, Kerman, Iran \\ Mohammad Rahimi \\ Geography and Urban planning, Humanism Science, Kerman Bahonar University, Kerman, Iran
}

\begin{abstract}
Seismic rehabilitation of structures subjected to earthquake is one of the most important engineering issues in earthquake-prone countries all over the world. Vast areas in the existing structures which are located in earthquake-prone areas do not enjoy enough seismic safety. The structure can be restored by using different rehabilitation techniques in order to avoid possible problems during severe earthquakes. There are several methods for seismic rehabilitation of structures and the designing engineer must select the most economical approach with the best performance during the earthquake. In this paper, at first the earthquake crisis has been defined and management methods have been expressed, through using library resources and qualitative-analytical methods. Then we have studied different buildings and their rehabilitation and renovation methods and finally we achieved a set of rehabilitation and crisis management strategies.
\end{abstract}

Keywords: earthquake, rehabilitation, worn textures.

\section{INTRODUCTION}

Urban worn textures suffer from several physical, environmental, social and economic problems which have made it difficult for their residents to live in these textures. According to the conducted studies, about $90 \%$ of the population of Iran is at risk of dangers of earthquake. Therefore, worn textures due to the existing problems are highly vulnerable in the event of earthquake. However, in the provision of worn textures rehabilitation projects and other urban projects, earthquake crisis management theories are used in order to provide strategies to reduce the vulnerability of the cities in the event of earthquake. Strategies that earthquake crisis management offers in order to reduce the vulnerability of urban areas are associated with the areas of urban planning system and especially rehabilitation of worn textures. Areas which are common among rehabilitation planning and earthquake crisis management include four areas of land use, access, density and open space. The purpose of this research is to study rehabilitation of urban worn textures, by investigating common strategies among two approaches of rehabilitation planning and earthquake crisis management; so that we could combine these two approaches in order to increase the quality of life in worn textures and to reduce their vulnerability in the face of earthquake crisis (Lantada, 2008).

\section{RESEARCH METHODOLOGY}

This research has been conducted based on analytical-descriptive research method, in a qualitative approach and based on library resources and studies, including articles, books, Internet Information and $\mathrm{MS}$ and $\mathrm{PhD}$ theses.

\section{THEORETICAL FOUNDATIONS OF RESEARCH:}

\section{CRISIS}

Submit Date: 10.05.2016, Acceptance Date: 25.06.2016, DOI NO: 10.7456/1060JSE/017

Copyright (C) The Turkish Online Journal of Design, Art and Communication 
Crisis is an event which suddenly happens due to the occurrence of natural or humane incidents and actions. Imposes difficulty, hardship and damage to a setting or a humane society and removing it requires extraordinary and emergency measures and operations.

In other words, system components establish relationships in the form of action and reaction, in a specific framework and based on measured and regulated standards and criteria. In any system, constituent elements should be maintained and protected within a certain scope; otherwise, system equilibrium will be disordered and even it may be completely eliminated. Crisis is a condition that disrupts the order of the original system or some parts of it and disrupts its stability. In other words, crisis is a situation which creates a sudden change in one or several parts of the system variables. Intensity and weakness of crises depends on aggravating or mitigating factors and available techniques for managing the crisis or to restrain it.

In terms of operational issues, we can analyze crisis as a system in which there are two sets of factors; medium and system structure and also other factors which cause the crisis. Determining the most vulnerable factors and elements of the system, in the face of crisis is one of the most important tasks of research on crisis management. Determining the most vulnerable part of system is indeed determining that part which requires the highest level of consideration and care (BAVAND Consulting Engineers, 2007).

\section{EARTHQUAKE CRISIS}

Everything around us is moving and we are generally satisfied with living on earth. Our stability is due to the earth under our feet, but the earth sometimes moves suddenly and this is the earthquake; that is an event that occurs without warning. Perhaps we can say that earthquake is the most frightening and deadliest natural disaster; because it begins suddenly and there is no time to escape. The earthquake usually begins when some pressures rupture the ground and shake it. But in the conventional sense, earthquake refers to the movements of the earth's crust on its mantle which compresses the earth's crust in some areas and then earthquake occurs by releasing energy through landslides, in the depths of the seas or on lands (BAVAND Consulting Engineers, 2007).

Crisis management refers to a set of interventions which must be conducted before, during and after the occurrence of an accident in order to reduce possible impacts and complications. Also crisis management includes planning, organizing, leadership, coordination, control and supporting urban vulnerability against natural disasters, such as earthquakes and it is a function of human behavior which indicates the degree of vulnerability or stability of socio-economic units and urban physical assets against natural hazards. Vulnerability is the probability of exposition of a person or group to adverse effects of a hazard (Clark, 1998).

Therefore, we must try to reduce human and environmental vulnerability by performing deliberate actions and by considering appropriate measures and try to extend confrontation with earthquake among different classes of societies. So, trying to find suitable impact reduction techniques has always been a part of human researches. Although these studies have mainly focused on construction techniques in order to set standards for foundation, building structure, ceilings, walls, type of materials, façade and ... in order to increase the resistance against earthquakes; however, in the study of earthquakes, buildings are considered only as a component of a bio-complex and other issues are concerned as well. In fact, a city can be designed with the aim of reducing vulnerability against earthquakes (Lantada, 2008).

\section{DEFINITION OF CRISIS MANAGEMENT}

Crisis management is an applied science which through systematic observation of crises and by analyzing them tries to find a tool to prevent crises or in the event of their occurrence take action to reduce the effects, conduct rapid helping and improve the situation (Ahmadi, 1996). 
On this basis, we can say that crisis management is a process to confront with difficult situation which mobilizes all the group plans, organizing and controls and offer them to managers who must act quickly but without hastiness to make their decisions. Crisis management may be necessary for any organization which encounters with internal and external pressures. These pressures force the manager to decide hastily.

\section{THE ROLE OF CRISIS MANAGEMENT IN EARTHQUAKE}

It is an applied science which analyzes past crises and utilizes science and technology in order to find a solution or a tool to prevent the crisis or to be prepared to confront it (Akbari, 2006).

\section{MEASURES INCLUDE:}

- Early warning to the residents

- Providing the needs of homeless refugees

- Maintaining public security

- Unloading event relics

- Restoring the community to the normal condition

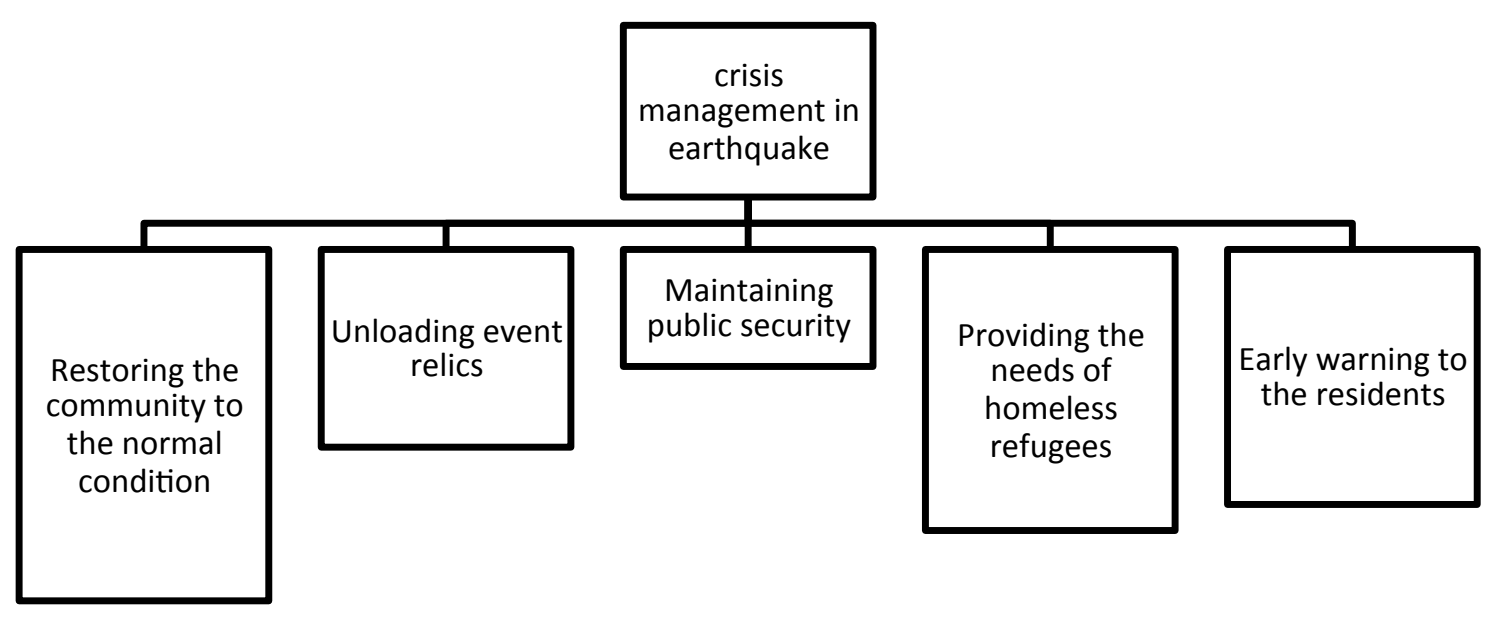

Fig1.Measures to manage the crisis in earthquakes

\section{URBAN WORN TEXTURES}

Urban worn textures are worn neighborhoods in the urban space with their issues and social, economic, cultural complexities and their special style. These neighborhoods and textures on the one hand enjoy invaluable residential roots with cultural, social and architectural richness and on the other hand, due to severe wearing, lack of proper access to urban and health services, social and security problems and vulnerability to earthquakes, floods and fires and incompatibility with today's urban life and modern urban development have their own super structural and infrastructural problems (Ahadnejad Roshti, 2010).

Worn texture refers to the blocks which have the following three conditions:

1. Instability: $50 \%$ of the existing buildings are located in unstable block and do not have the necessary strength. 
2. Impermeability: at least $50 \%$ of passages have less than 6 meters width.

3. Small buildings: at least $50 \%$ of buildings in that city block have an area less than 200 square meters.

Worn textures are divided into three major categories:

A - Textures with cultural heritage

B - Urban textures (without cultural heritage)

C - Marginal textures (informal settlements) (Housing Foundation of Islamic Revolution, 1994).

Different phases of crisis management, in terms of time and operations:

1. Pre-crisis

2. At the beginning of crisis

3. During crises

4. After crisis.

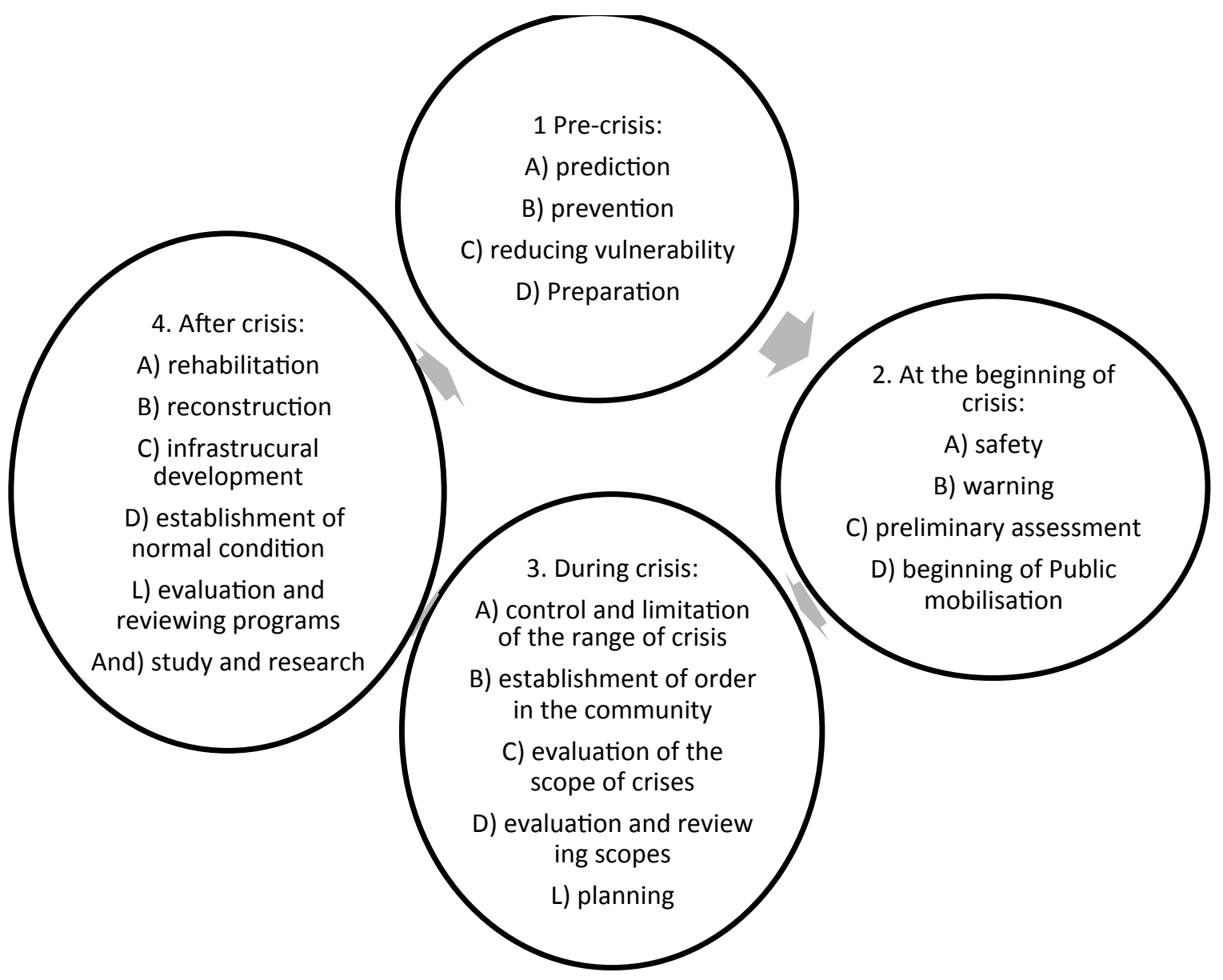

Fig2. The main cycle of crisis management 


\section{THE NECESSITY AND IMPORTANCE OF PREPAREDNESS AGAINST EARTHQUAKE HAZARDS}

Each year natural disasters cause terrible economic losses and human casualties in different countries. The extent of these damages and losses in different societies depends on the level of development and population density, safety of buildings in villages and towns to confront earthquake and awareness and preparedness of individuals and society to observe safety measures. One of the major natural disasters is earthquake and it is not currently possible to predict the exact time and place of its occurrence and scientists' attempts to realize this issue are still in the research phase.

For this reason, sudden occurrence of earthquake in most cases surprises human communities and particularly those which ignore the likelihood of its occurrence and do not meet earthquake safety measures and it will leave unfavorable outcomes. Iran is located on the active seismic belt of Alps Himalayas and it is among the earthquake-prone regions in the world and occasionally a devastating earthquake occurs in different parts of it (Standards Development Office, 1389).

International experience shows that in addition to observing principles of proper urbanism in earthquakeprone regions, damages caused by earthquake can be reduced by training and by observing safety measures.

\section{REHABILITATION AND RENOVATION}

Urban restoration can be performed in three main ways which include rehabilitation, renovation and reconstruction and we will define them in the following sentences. Rehabilitation: "Rehabilitation includes a series of measures which is being performed in order to improve the structure, in the short term to rehabilitate problems caused by wearing" (Ahadnejad Roshti, 2010).

Renovation "Renovation will be performed, when the urban space, the complex or the building still has its proper functionality; but its relative spatial and physical wearing decreases its efficiency and performance" (Milutinovic, 2003).

Reconstruction: "Reconstruction means to rebuild. Reconstruction takes place when in building, complex or urban space series, total wearing occurs. Total wearing occurs due to (partial or total) wear of both the structure and performance" (Habibi, purpose, 1338: 21). However, in this study, we have mainly focused on renovation and rehabilitation, rather than reconstruction. "Major objectives of renovation of worn urban areas include: securing, balancing, vivification and capacity building" (Pourahmad, 2007).

Now that we mentioned major objectives of renovation, now we must express principles of renovation. Principles of renovation of worn urban areas include: people-orientation, holistic thinking, comprehensive view, and process-orientation, motivating participation, modeling, opportunity-orientation, assurance (building trust) and institutionalization (Ahmadi, 1996).

The most important issue regarding worn textures is maintenance, so that residents do not let the buildings to wear and to prevent it by proper maintenance. When people themselves care about rehabilitation and renovation, they will prevent wearing and wearing. Also, municipal managers and officials must develop encouraging policies and support disadvantaged people and encourage them to protect and service their residential textures and if there was any need for rehabilitation and renovation of urban textures, they must develop plans (under any title but effective) in order to improve the quality of life of people. Another issue is not creating worn textures in future projects, which require the attention of designers and urban planners in urban development projects in order to prevent construction of worn urban textures. Regarding the issue of informal settlement which is a sub-discipline of worn textures, the first solution is prevention and then we must plan for rehabilitation and renovation. Disregarding the issue of informal settlement, not only doesn't prevent the growth and development of these areas, but it further extends these areas. In the beginning and for prevention we must consider items such as rural 
development and development of small towns. Preventing indiscriminate migrations to big cities is preventing from invasion to informal areas. Since the ownership of worn textures' lands inside the cities are not illegal - unlike marginal areas- and their target population are different; so rehabilitation, renovation and organization of these areas have similarities and differences, as well. Strategies to organize informal settlement areas: 1. Rehabilitation of marginal areas, 2. Renovation of marginal areas (if not rehabilitated), 3. Displacement and resettlement in new places, 4.Preparing the grounds to return people to their native lands (Lotfi et al., 1332: 142). In Table 1, common techniques for rehabilitation, renovation and organization of urban textures without special historical-cultural heritage and marginal areas will be studied and then in Table 2, specific techniques for organizing marginal textures will be discussed (Standards Development Office, 1389).

\section{BASICS OF REHABILITATION}

Basics of rehabilitation used in the guideline of seismic rehabilitation of existing buildings are based on evaluation and rehabilitation of building performance. In this regard, the purpose of rehabilitation well be defined and based on the desired level of building's performance, the rehabilitation purpose will be selected.

Selecting rehabilitation purpose and designing based on the level of building's performance, to achieve the desired level of performance should be performed based on evaluation and rehabilitation principles (Mo'tamedi, 1390).

Different phases of evaluation and rehabilitation

- Study and identification of technical characteristics of building

- Selecting the purpose of rehabilitation

- Collecting information on current status of building

- The necessity for rehabilitation

- Selecting evaluation and rehabilitation method

- Providing rehabilitation plan and evaluating it

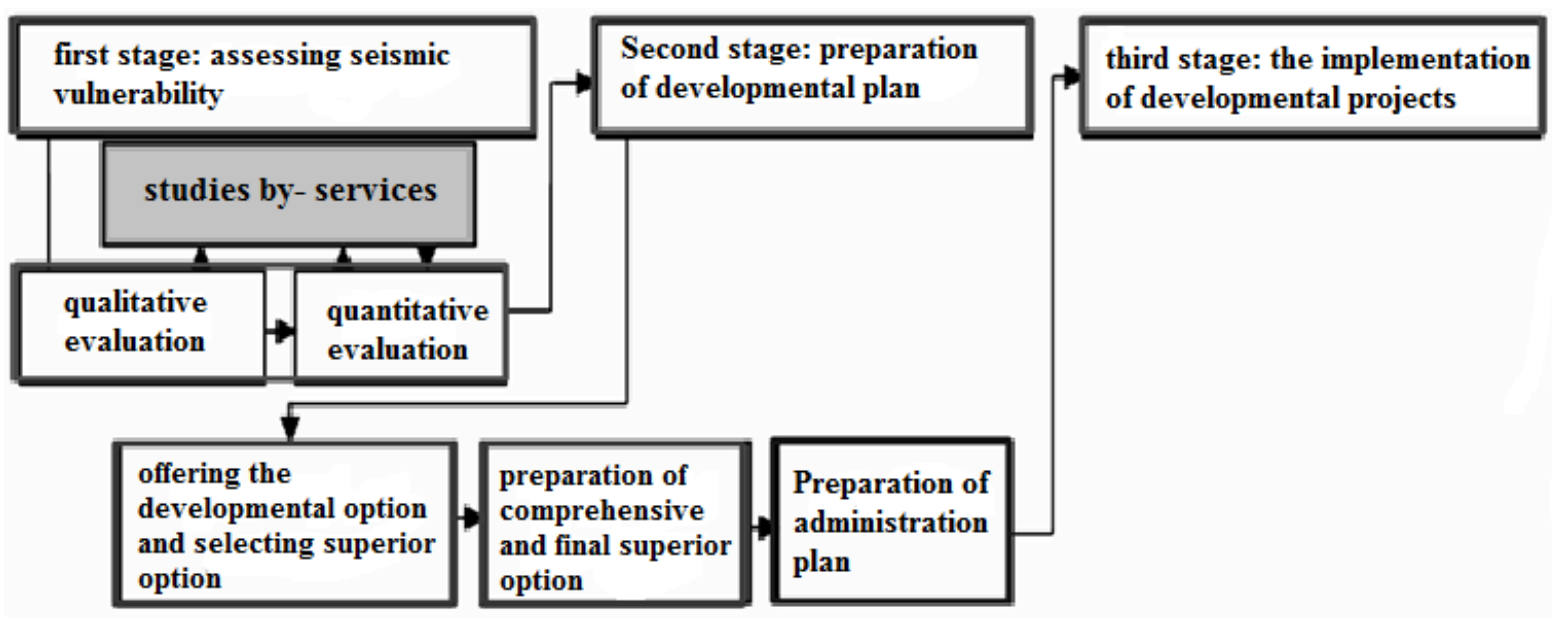

Fig3. : seismic developmental process chart 
Primary phases of evaluation of seismic resistance and the need for seismic rehabilitation of buildings are as follows:

1- Studying primary considerations:

- Structural specifications

- Earthquake hazards in the building

- Uses and applications

- The results of initial evaluation of seismic resistance

- Historical considerations

- Economic and cost considerations

- Social consequences (lecture on impacts of earthquakes on buildings, 1390).

2. Selecting the purpose of rehabilitation, based on the importance and performance of building which includes the following types:

\section{- Basic rehabilitation:}

In this state, it is expected to provide an average level of safety for occupants of the building that is equivalent to a level of strong ground motions which the probability of their return is 10 percent in 50 years.

The cost of retrofitting the building in this type is mediocre.

\section{- Desired rehabilitation:}

At this level it is expected in addition to providing basic target sanitation, the performance level of collapse verge is relatively good in building under earthquake ground motions that likely led process is equivalent to a level of $2 \%$ in 50 years. The cost of retrofitting buildings of this type is relatively high.

\section{-Special rehabilitation:}

in Special rehabilitation it is expected in the building compared to the "ideal" of a higher performance level to be under the same level of earthquake risk or maintaining the same level of performance is taken as the risk of higher earthquake for standard practice.

\section{- Local rehabilitation:}

If for some reason the possibility of a complete rehabilitation of the building is not possible, rehabilitation operations may be performed in several stages. Local rehabilitation should not create disruption in the functioning of the entire building or continuing rehabilitation operations. At each stage, local rehabilitation may be carried out at the level of "basic rehabilitation ", "special rehabilitation " or "limited rehabilitation ".

Local rehabilitation should be done according to the following factors: - Building's local rehabilitation should not lead to lower performance levels of previously existing buildings. 
- Local rehabilitation should not increase the earthquake forces in the components in which are in critical condition.

1. Local rehabilitation should not lead to irregularity or increasing the irregularity of buildings (the journal Earthquake Research Institute, 1390).

3. Recognition of the status quo and local information

4. Selecting the rehabilitation strategy or method

5. Planning of rehabilitation's measures

6. Reviewing and approval of rehabilitation measures

\section{REHABILITATION STRATEGIES}

The following strategies can be used either alone or in combination with each other to improve building used:

\section{Local rehabilitation of structural components that have poor performance in earthquake.}

When after the evaluation of seismic evaluation and investigation of acceptance criteria it is identified just some of the structural components do not have sufficient capacity to withstand the forces and deformations, the local rehabilitation can be used as a proper way of rehabilitation for preparing the building to the expected level both in terms of resistance and roughness.

\section{Removing or reducing irregularities in existing buildings}

If the seismic evaluation indicates that there are irregularities in the building block the building to meet the expected performance level and the elimination or reduction of building components disorder, does not estimate sufficient capacity both in terms of resistance and in terms of roughness for that level of performance. In this case, the above method will be an effective way for rehabilitation (which will be used as possible alternative methods).

Irregularities in the building may be due to discontinuities in the lateral components. In these cases, the change in lateral loading system and creating continuity may reduce irregularities of building. Of course this solution in some buildings (monuments) may not be possible.

Modification or reduction in buildings disorders with soft or weak floors can be done by adding bracing in the floors for fitting the lateral stiffness of mentioned classes with other classes. In the case of cyclical irregularities adding the lateral loading components in order to reduce the distance of mass center the roughness center can be effective in reducing the irregularity (including mechanical methods, industrial or building) (setting standards office, 1389)

\section{Providing the required lateral stiffness to the structure}

when it is determined that the building does not have sufficient stiffness for a given performance level caused by seismic assessment adding bracing or shear walls can be an effective way to address this deficit.

\section{4. supplying the required resistance for the entire structure}

In cases where the majority of the structural components of the building do not have the acceptance criteria relating to expected performance levels, it is necessary for the entire building, lateral system with sufficient capacity to be created it is necessary for the entire building that lateral system with sufficient capacity is created.

Submit Date: 10.05.2016, Acceptance Date: 25.06.2016, DOI NO: 10.7456/1060JSE/017 


\section{Reduction of building mass}

When after the seismic assessment it is determined that building does not have sufficient lateral stiffness or the vast majority of enough resistance components for selected operation level using reduction mass to be used as a suitable method.

\section{Using seismic isolation systems}

If the results of the assessment indicate insufficient hardness and resistance to seismic performance level of choice or protection of important equipment and non-structural building components is desired, using seismic isolation system would be suitable for suitable rehabilitation solutions.

\section{Using of passive energy dissipation systems}

In cases where a seismic assessment of buildings indicate the building does not have sufficient lateral stiffness for the selected action or embedded components for building energy-absorbing structural deformations can be limited (Journal of Earthquake Research Institute, 1390.

\section{8. changing the usage of Building}

Since most buildings are made of old texture of the masonry or brick, the following ways are for rehabilitation of these structures:

\section{Administrational strategies in masonry buildings:}

1. Steel net and shotcrete method: bars are put in the foundation at determined intervals and meshing is done on the wall. After that sprayed concrete operation carried out at least $3 \mathrm{in} \mathrm{cm}$ thickness.

2. The method of using concrete buttresses: in this method, at the intersection of longitudinal and lateral of the walls as well as vertical place of foundations that usually exist as symmetrical and regular in buildings a 35 to $50 \mathrm{~cm}$ concrete buttress is incorporated.

3. The use of polymer fibers: this method is done like Steel grid network but instead of using steel grid polymer fibers are used (Journal of Earthquake Research Institute, 1390)

\section{ADMINISTRATIONAL STRATEGIES IN THE MASONRY BUILDING:}

1. Structural forms: geometric shape of a building is the most important factor in its stability against earthquake, so it should be tried as much as possible the construction plan is in the simple and symmetrical form and in two vertical directions the perpendicular without much concavity and protuberance and the creation of asymmetric changes in elevation also is avoided.

2. Structural integrity: all the load-bearing building elements should be interconnected properly in which they are not isolated from each other when earthquakes happen and building works seamlessly. In this regard, rewinding system is used in masonry buildings.

3. Building Technology Development: Strengthening of existing buildings is used by different materials such as strengthening horizontal and vertical reinforcement, wooden boards, interconnected meshes etc.

4. The use of horizontal and vertical reinforcement: reinforcement creates expandability and ductility in materials. Vertical reinforcements help connecting the wall to the foundation and inhibit bending and shear forces. Horizontal reinforcements help transferring bending and shear forces from shear walls to crossover walls and also avoids shear stresses between adjacent walls and propagation of vertical cracks. 
5. Use of bars and coils walls: the walls are usually made at the junction of the wall in the form of a plus which also makes buildings resistant from each side and will increase its resistance to thrust earthquake.

6. The quality of masonry blocks creation: the quality of synthetic material depends on the quality of masonry block and brick buildings have a huge impact on strength (standard setting Bureau, 1389)

\section{CONCLUSION}

In this paper, after defining crisis and crisis management, expressing the importance of earthquake hazard in Iran and referring to the basic problems of our country in this regard, the major weaknesses of earthquake crisis management in Iran were discussed and finally some suggestions were offered to resolve a major part of these weaknesses. The main results of this paper briefly include:

1. Seriousness of earthquake hazard in Iran and the possibility of continuing heavy casualties and damages due to earthquake

2. Numerous problems, regarding confrontation with earthquake in Iran due to major weaknesses in earthquake crisis management attitudes and methods

3. The need for basic revision in country's earthquake crisis management, by using the experience of successful countries, like Japan

4. Establishment of natural crisis management organization, information management and earthquake alerts center, separating priorities of confrontation and expansion of public trainings are among the most important suggestions in this revision.

5. Culture-building and training human resources are considered as the cornerstones of comprehensive crisis management and the most basic priorities.

Suggestions for basic revision in earthquake crisis management in Iran

New decisions by authorities to evaluate current status of our country, in confrontation with earthquake and organizing it after the earthquakes of Bam and Baladeh and using the experiences of Japan in this regard are examples of proper orientations for earthquake crisis management in the future. Integration of these two approaches can make the current status and the desired status more transparent and it can facilitate our movement toward the desired status. The author believes that, Iran requires a fundamental revision in its thinking and methods in confrontation with earthquake and presents the following suggestions as the most important items, in this regard:

- Establishment of natural crisis management organization in the country

- Establishment of center of information management of natural crisis

- The need for preference of managerial attitude over engineering attitude in confrontation with earthquake

- The need for separation of priorities in confrontation with earthquake

- Public training and communication

- Culture-building and training human resources (the most important priority) (Farhad Bozorgi- 16 Secretary of crisis management staff, District 16 of municipality).

Also in this article, different steps of evaluation and rehabilitation are expressed as follows: 
- Study and identification of technical characteristics of building

- Selecting the purpose of rehabilitation

- Collecting information on current status of building

- The necessity for rehabilitation

- Selecting evaluation and rehabilitation method

- Providing rehabilitation plan and evaluating it

Rehabilitation strategies were also expressed as follows:

1. Modification of structural components with poor performances in earthquakes

2. Removing or reducing disorders in existing buildings

3. Providing necessary lateral stiffness for the entire structure

4. Providing necessary resistance for the entire structure

5. Reducing the mass of building

6. Using seismic isolation systems

7. Applying passive energy dissipation systems

8. Changing building use

Finally, executive strategies were expressed for masonry buildings and brick buildings which have been common in the past and require more renovation and rehabilitation.

\section{REFERENCES}

Earthquake and Seismology Institute publication, Issue Two, Summer 1390

Earthquake and Seismology Institute publication, Issue III, Summer 1390 Mo'tamedi, Mehrtash and colleagues, damages to buildings of adobe and Building, Institute of Seismology,

Nazemi Elahi, F., design and execution of masonry buildings earthquake resistant, Tehran, lighting, 1389 vafamehr, M., advanced manufacturing techniques, the Faculty of Architecture, University of Science and Technology, Department of Architecture, 1385 office to develop standards, guidelines seismic retrofitting existing buildings Tehran, Management Planning, 1389

Training Seminar Lectures series of earthquakes in conventional buildings, Number 67, Building and Housing Research Center, 1390

Ahadnejad Roshti, M., 2010, Modeling Urban Vulnerability to Earthquakes: A Case Study of Zanjan, Ph.D Dissertation in Geography and Urban Planning, School of Geography, Tehran University, Tehran. (In Persian)

Ahmadi, M., 1996, Role of Urban Planning and Urban Design in Mitigation and Crisis Management, Proceedings of the International Conference, Volume II, Tehran. (In Persian)

Akbari, R., 2006, The Role of Urban Planning Earthquake Crisis Management Using GIS and RS: A Case Study FARAHZAD Tehran, M.S Thesis, Supervisor: Azizi, M., Urban School of Fine Arts, Tehran University, Tehran. (In Persian)

BAVAND Consulting Engineers (Design Detail Area 12), 2007. (In Persian) 
Botero. V., 2009, Geo-Information for Measuring Vulnerability to Earthquakes, Utrecht University Repository, Netherlands.

Ahadnejad Roshti, M., Gharakhlou, M. and Ziyari, K., 2010, Modeling of the Seismic Vulnerability of Building Cities Using AHP in GIS, Geography and Development Journal, No. 19. (In Persian)

Clark, G. E., Moser, S. G., Ratick, 1998, Assessing the Vulnerability of Coastal Communities to Extreme Storm: The Case of Revere, MA, USA.

George J. M., 2002, Seismic Parameters Used in Land Use Planning, Scheduling and Implementation of the Relevant Laws and Regulations, Conference, Stanford.

Housing Foundation of Islamic Revolution, 1994, The Shape and Size Desired in order to Reduce Vulnerability due to Earthquake Engineering Design can be Mobilized to Deal with the Effects of the Earthquake, Research Director: Seyed Hossein Bahrain, Tehran. (In Persian)

Lantada, N., Pujades, L. and Barbat, A., 2008, Vulnerability Index and Capacity Spectrum, Based Method for Urban Seismic Risk, Evaluation Journal of Nathazards, Doi 10-007 11069 007-9212-4.

Little, M., Paul, K., Jorderns, C. F. and Sayers, E. J., 2002, Vulnerability in the Narrative of Patients and Their Cares: Studies of Colorectal Cancer, Health, Vol. 4, No. 4, PP. 425-510.

Milutinovic, Z. V. and Trendafiloski, G. S., 2003, WP4 Report: Vulnerability of Current Buildings. RISK UE Project: An Advanced Approach to Earthquake Risk Scenarios with Applications to Different European Towns, Polytechnic University of Catalonia, Barcelona, Spain.

Pourahmad, A., Habibi, K. and Meshkini, A., 2007, Urban Development and Renewal of Old Tissue, Kurdistan University Press, Sanandaj. (In Persian)

Smith, K., 1996, Environmental Hazards: Assessing Risk and Reducing Disaster, London, Routledge. Yamazaki Fumio, 2005, Building Damage Mapping of the Ban, Iran, Earthquake Using ENVISAT /ASAR Intensity Imagery, Earthquake Spectra, Vol. 21, No. S1, PP. S285-S294, 12.

Yashy, Cuba, 2004, Vulnerability and Retrofitting Buildings in Tehran, Iran-Japan Joint Workshop Proceedings, Publication, No. 298, Management and Planning Organization, Tehran. (In Persian)

Darbak, Thomas E.(1990) Emergency Management: Strategies for maintaining Organizational Integrity. New York: Springer-Verlag. 25. 28.Adini.M(1993). Disaster Management in Metropolitan Area 21th Century. International Conference, Nagao ya , Japan.

Gharakhlou, M.,(2007),An application of SMCDA model in urban services: A case study of Ahvaz city, IRAN; THE DECCAN GEOGRAPHER, Vo.45, No.1, p.19-25.

Rattien Stephen. (1990) the Role of media in Hazard Mitigation \& Disaster Management, Disaster Press , Voll

Wang, Xinhao \& Rainer vom Hof, (2007) Research Methods in urban and Regional Planning, Springer Chapin, S, 1979. Urban Land use Planning, New York. 27

Falamaki, S 1384. Urban renwal and repairmen. Tehran: SAMT publication.

Geddes, P 1950. Civies:as Applied Sociology. Paris: Springer Ltd.

Rahnama, et al. 2005 Accessibility and Sustainability in Sydney, International.Conferences of Health Risk. Blonya, Italy, 356-370.

Trancik, Roger 1981 " Finding lost space- theories of urban design 